\title{
Retraction Note: Seven spices of India-from kitchen to clinic
}

Vinod Kumar ${ }^{*}$ (1)

Retraction Note: J. Ethn. Food 7, 23 (2020).

https://doi.org/10.1186/s42779-020-00058-0

The Editor-in-Chief has retracted this article because, upon further review, in their judgment the article proffers insufficient critical assessment of the material presented and literature cited, which, in their view, invalidates the conclusions drawn. Vinod Kumar has not responded to correspondence from the Publisher about this retraction.

\section{Publisher's Note}

Springer Nature remains neutral with regard to jurisdictional claims in published maps and institutional affiliations.

Published online: 09 September 2021

The original article can be found online at https://doi.org/10.1186/s42779020-00058-0.

*Correspondence: vinodchauhan.4u@gmail.com

Amity School of Hospitality, Amity University, Gurugram, Haryana, India 